\title{
Possible influence of atmospheric circulations on winter haze pollution in the Beijing-Tianjin-Hebei region, northern China
}

\author{
Z. Zhang ${ }^{1,2}$, X. Zhang ${ }^{1,2}$, D. Gong ${ }^{3}$, S.-J. Kim ${ }^{4}$, R. Mao ${ }^{3}$, and X. Zhao ${ }^{1}$ \\ ${ }^{1}$ Environmental Meteorology Forecast Center of Beijing-Tianjin-Hebei, Chinese Meteorological Administration, Beijing \\ 100089, China \\ ${ }^{2}$ Institute of Urban Meteorology, Chinese Meteorological Administration, Beijing 100089, China \\ ${ }^{3}$ State Key Laboratory of Earth Surface Processes and Resource Ecology, Beijing Normal University, Beijing 100875, China \\ ${ }^{4}$ Korea Polar Research Institute, Incheon 406-840, Korea
}

Correspondence to: Z. Zhang (zzy_ahgeo@163.com) and X. Zhang (xlzhang@ium.cn)

Received: 30 July 2015 - Published in Atmos. Chem. Phys. Discuss.: 21 August 2015

Revised: 21 November 2015 - Accepted: 16 December 2015 - Published: 19 January 2016

\begin{abstract}
Using the daily records derived from the synoptic weather stations and the NCEP/NCAR and ERA-Interim reanalysis data, the variability of the winter haze pollution (indicated by the mean visibility and number of hazy days) in the Beijing-Tianjin-Hebei (BTH) region during the period 1981 to 2015 and its relationship with the atmospheric circulations at middle-high latitude were analyzed in this study. The winter haze pollution in BTH had distinct inter-annual and inter-decadal variabilities without a significant long-term trend. According to the spatial distribution of correlation coefficients, six atmospheric circulation indices ( $I_{1}$ to $\left.I_{6}\right)$ were defined from the key areas in sea level pressure (SLP), zonal and meridional winds at $850 \mathrm{hPa}$ (U850, V850), geopotential height field at $500 \mathrm{hPa}(\mathrm{H} 500)$, zonal wind at $200 \mathrm{hPa}$ (U200), and air temperature at $200 \mathrm{hPa}$ (T200), respectively. All of the six indices have significant and stable correlations with the winter visibility and number of hazy days in BTH. In the raw (unfiltered) correlations, the correlation coefficients between the six indices and the winter visibility (number of hazy days) varied from $0.57(0.47)$ to $0.76(0.6)$ with an average of 0.65 ( 0.54$)$; in the high-frequency $(<10$ years) correlations, the coefficients varied from $0.62(0.58)$ to $0.8(0.69)$ with an average of $0.69(0.64)$. The six circulation indices together can explain $77.7 \%$ (78.7\%) and $61.7 \%$ (69.1\%) variances of the winter visibility and the number of hazy days in the year-to-year (inter-annual) variability, respectively. The increase in $I_{\mathrm{c}}$ (a comprehensive index derived from the six individual circulation indices) can cause a shallowing of the East Asian trough at the middle troposphere and a weaken-
\end{abstract}

ing of the Siberian high-pressure field at sea level, and is then accompanied by a reduction (increase) of horizontal advection and vertical convection (relative humidity) in the lowest troposphere and a reduced boundary layer height in BTH and its neighboring areas, which are favorable for the formation of haze pollution in BTH winter, and vice versa. The high level of the prediction statistics and the reasonable mechanism suggested that the winter haze pollution in BTH can be forecasted or estimated credibly based on the optimized atmospheric circulation indices. Thus it is helpful for government decision-making departments to take action in advance in dealing with probably severe haze pollution in BTH indicated by the atmospheric circulation conditions.

\section{Introduction}

The Beijing-Tianjin-Hebei (BTH) region is located in northern China, with approximately 110 million residents and $216000 \mathrm{~km}^{2}$ in size. With the rapid progress of urbanization and industrial development over the past 3 decades, the BTH region has become one of China's most economically developed regions and the third economic engine in China. Recently, the Chinese government has been promoting the integration of the three neighboring regions to optimize the industrial layout and improve the allocation of resources. Undoubtedly, the BTH region is becoming more and more important in China or even the world economy in the future. However, the rapid economic growth and urbanization have 
increased the level of air pollution in recent decades (Streets et al., 2007; Chan and Yao, 2008; Y. Wang et al., 2009; T. Wang et al., 2010; Gao et al., 2011). Most of eastern China has frequently suffered from severe haze or smog days in recent years, especially in the BTH region. For example, the continuous haze pollution in January 2013 greatly threatened human health and traffic safety (Kang et al., 2013; Wang et al., 2013). Roughly speaking, the haze pollution can be attributed to two aspects: pollutant emissions into the lower atmosphere from fossil fuel combustion or construction and favorable meteorological conditions. Meteorological conditions are controlling the occurrence of haze pollution ( $\mathrm{Wu}$, 2012; Zhang et al., 2013). Specifically, weather conditions play an essential role in the daily fluctuation of air pollutant concentrations (Z. Y. Zhang et al., 2015).

At present, many studies have focused on the physical and chemical properties of pollutants in Beijing and other cities (Feng et al., 2006; Yu et al., 2011; Xu et al., 2013; Zhao et al., 2013). And studies also demonstrated the influence of weather conditions or synoptic situations upon air pollution (Zhao et al., 2009; Z. Y. Zhang et al., 2015). They elucidated clearly the formation and chemical composition of air pollutants and the dominant meteorological factors during heavy pollution in the BTH region. On the other hand, some studies demonstrated that the haze pollution occurring in the BTH region could be strongly affected by the local atmospheric circulations including sea-land and mountain-valley breeze circulations and the planetary boundary layer height (Lo et al., 2006; Liu et al., 2009; Chen et al., 2009; Miao et al., 2015). Recently, Wang et al. (2015) suggested that the reduction of autumn Arctic sea ice leads to anomalous atmospheric circulation changes that favor less cyclone activity and a more stable atmosphere, leading to more hazy days in eastern China. Moreover, Wang et al. (2013) showed that eastern China suffered from severe haze pollution in January 2013 that may be due to a sudden stratospheric warming over the mid-high latitude of the Northern Hemisphere, which led to an anomalous steady atmosphere that dominated in northern China. Thus, it is interesting to examine whether the winter haze pollution in BTH has been influenced by other known or unknown atmospheric circulations or teleconnections in the mid-high latitude of the Northern Hemisphere and whether there are some potential circulations that can be used for the forecast or evaluation of the winter haze pollution in BTH. To date, there is no clarity on these questions, and a few studies have been performed to explore these issues.

Owing to a lack of long-term instrumental records for air pollutant concentration, the understanding of the evolution of air pollution and their relations to atmospheric circulations is limited. In this paper, we intend to use the atmospheric visibility and the number of hazy days derived from the synoptic meteorological stations to denote the evolution of haze pollution in the BTH region since the 1980s. Many studies demonstrated that, in the absence of certain weather conditions (e.g., rain, fog, dust and snowstorm), the visibility is an excellent indicator of air quality because its degradation results from light scattering and absorption by atmospheric particles and gases that can originate from natural or anthropogenic sources (Baumer et al., 2008; Chang et al., 2009; Sabetghadam et al., 2012; Baddock et al., 2014), although visibility was influenced comprehensively by airborne pollutants and meteorological parameters such as relative humidity, wind speed, temperature, pressure and solar radiation (Wen and Yeh, 2010; Deng et al., 2014; Q. Zhang et al., 2015).

The main purpose of this study is to examine the possible relations between the atmospheric circulations and the winter haze pollution (the mean visibility and mean number of hazy days) over the BTH region and investigate the possible physical mechanism, which could be useful for a prediction of the winter haze pollution and could provide a scientific support to the government to take effective measures in advance to reduce or control the pollutant emission in case of an anomalous circulation leading to serious haze pollution in the region. This paper is organized as follows. Section 2 describes the data and method used. Section 3 shows major results and discussions. The conclusion is summarized in Sect. 4.

\section{Data and methods}

\subsection{Research area and station data}

The atmospheric visibility recorded at the 19 synoptic meteorological stations located in the research area from 1 January 1980 to 28 February 2015 was used (Fig. 1). The visibility by human observers is recorded four times (02:00, 08:00, 14:00 and 20:00, Beijing local time) or three times (08:00, 14:00 and 20:00, Beijing local time) per day. A good continuous monitoring operation was maintained throughout the entire period, with the missing data rates for the 19 stations varying from a minimum of $1.7 \%$ to a maximum of $2.1 \%$, with a mean of $1.9 \%$. On the other hand, the distribution of the stations is relatively uniform, indicating that the mean visibility or hazy days are a good representative of the whole BTH region.

In the present study, the days with visibility $\leq 5 \mathrm{~km}$ and relative humidity $<90 \%$ at 14:00 (local time) were defined as hazy days, except for the special weather phenomena that occurred at this moment including rain, fog, dust and snow (Schichtel et al., 2001; Wu et al., 2014). The mean number of hazy days $(\overline{\mathrm{NHD}})$ of each winter in the BTH region can be calculated by

$\overline{\mathrm{NHD}}=\frac{1}{n} \sum_{i=1}^{n} N_{i}$,

where $n$ is the number of stations (here $n=19$ ), and $N$ denotes the number of hazy days in a station in each winter (December, January and February). The mean visibility ( $\overline{\mathrm{Vis}}$ ) 


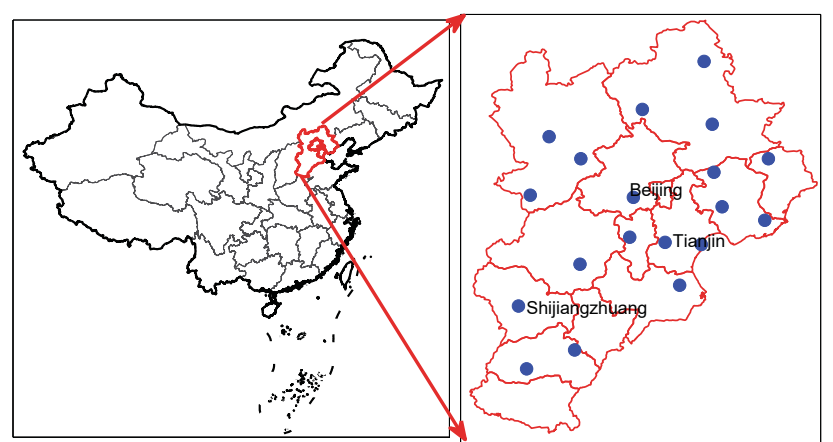

Figure 1. Research area and locations of the 19 synoptic meteorological stations.

of each winter in the BTH region can be calculated by

$\overline{\mathrm{Vis}}=\frac{1}{n} \sum_{i=1}^{n}\left(\frac{1}{m} \sum_{j=1}^{m} V_{i j}\right)$,

where $n$ is the number of stations (here $n=19$ ), and $m$ is the number of valid days in winter. It should be noted that the winter in 1981 consists of December 1980, January and February 1981, and so on.

\subsection{Reanalysis data}

The global NCEP/NCAR reanalysis data of the monthly sea level pressure (SLP), zonal and meridional winds at $850 \mathrm{hPa}$ (U850, V850), geopotential height field at $500 \mathrm{hPa}$ (H500), zonal wind at $200 \mathrm{hPa}$ (U200) and air temperature at 200, 150, 100 and $70 \mathrm{hPa}(\mathrm{T} 200, \mathrm{~T} 150, \mathrm{~T} 100, \mathrm{~T} 70)$ with a $2.5^{\circ} \times 2.5^{\circ}$ spatial resolution from January 1980 to February 2015 were used (Kalnay et al., 1996). Moreover, in order to obtain a higher spatial resolution in the BTH region, the ERA-Interim reanalysis data of the monthly relative humidity $(\mathrm{RH})$, vertical speed $(W)$, zonal $(U)$ and meridional $(V)$ winds from 1000 to $500 \mathrm{hPa}$ (16 pressure levels in total) and the boundary layer height $(\mathrm{BLH})$ with a $0.125^{\circ} \times 0.125^{\circ} \mathrm{spa}-$ tial resolution confined to the area $33-45^{\circ} \mathrm{N}$ and $110-122^{\circ} \mathrm{E}$ were also used (Dee et al., 2011).

\subsection{Analysis method}

For the statistical and atmospheric circulation analyses carried out in the study, the common statistical methods such as the composite analyses, the least square regression and the Pearson correlation analyses with a two-tailed Student's $t$ test were applied in this research. A principal component analysis (PCA) was also used to extract the principal mode of multiple time series. Moreover, in order to reduce the possible effects of low-frequency variation or long-term trends and to examine whether or not the correspondence between the two time series on an inter-annual timescale is stable, the high-frequency $(<10$ years) correlation of the high-pass

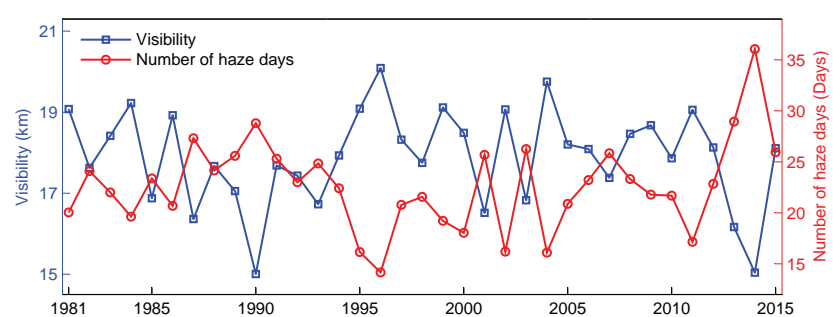

Figure 2. Curves of the winter mean visibility and number of hazy days in BTH.

filtered time series was also tested for time series analyses (Gong and Luterbacher, 2008; Zhang et al., 2010).

\section{Results and discussions}

\subsection{Evolution of the winter visibility and hazy days in the $\mathrm{BTH}$ region}

The regional mean visibility and number of hazy days in winter in BTH were presented in Fig. 2. As expected, the visibility was negatively correlated with the number of hazy days, with raw and high-frequency ( $<10$ years) correlation coefficients between them of -0.91 and -0.93 , respectively. Both of them are significant at the 0.01 level ( $p<0.01$ for short). More hazy days generally denote lower mean visibility in winter due to the light scattering and absorption effects of air pollutants (Baumer et al., 2008; Sabetghadam et al., 2012). There are intense inter-annual fluctuations in both the visibility and the number of hazy days over the entire period of 1981 to 2015 . The decadal fluctuations can also be distinguished for both the visibility and the number of hazy days throughout the entire period. A significant reducing trend of visibility $(p<0.05)$ and an increasing trend of the number of hazy days $(p<0.01)$ dominated in the 1980s. And then, the visibility experienced an increasing trend in the 1990s and a decreasing trend from 2001, and the hazy days showed an anti-phase change, but none of them are statistically significant, with the exception of the number of hazy days trend in the 1990s $(p<0.05)$. The mean visibility maximum in the 1990s reached $18.3 \mathrm{~km}$ (larger than the mean value of $17.9 \mathrm{~km}$ over the entire period), and the minimum number of hazy days in the 1990s reached 20.6 (less than the mean value of 22.7 days over the entire period). However, the long-term trends of them are not statistically significant, although weak reducing and increasing trends can be found in the curves of winter visibility and the number of hazy days, respectively.

\subsection{Relationship between haze pollution and atmospheric circulations}

We first examined the correlation coefficients between the visibility and number of hazy days and the most common atmospheric teleconnection or oscillation indices over the 
Table 1. Correlation coefficients of visibility and hazy days and circulation indices.

\begin{tabular}{lrrrrrrr}
\hline & & AO & NAO & PNA & EU & WP & SBH \\
\hline Visibility & $r 1$ & -0.11 & 0.00 & 0.16 & $0.61^{\mathrm{a}}$ & $0.40^{\mathrm{b}}$ & $0.39^{\mathrm{b}}$ \\
& $r 2$ & 0.05 & 0.22 & 0.16 & $0.71^{\mathrm{a}}$ & $0.37^{\mathrm{b}}$ & $0.36^{\mathrm{b}}$ \\
\hline Number of hazy days & $r 1$ & 0.13 & 0.13 & -0.10 & $-0.51^{\mathrm{a}}$ & $-0.47^{\mathrm{a}}$ & -0.32 \\
& $r 2$ & -0.01 & -0.11 & -0.10 & $-0.70^{\mathrm{a}}$ & $-0.56^{\mathrm{a}}$ & $-0.37^{\mathrm{b}}$ \\
\hline
\end{tabular}

${ }^{\text {a }}$ Significant at the 0.01 level. ${ }^{\mathrm{b}}$ Significant at the 0.05 level. The $r 1$ and $r 2$ terms indicate the raw correlation and high-frequency $(<10$ years) correlation, respectively.

mid-high latitude of the Northern Hemisphere (see Table 1), which could affect the winter climate variability over China, such as the Arctic Oscillation (AO), the North Atlantic Oscillation (NAO), the Pacific-North American pattern (PNA), the Eurasian pattern (EU), the Western Pacific pattern (WP) and the Siberian high (SBH) (Wallace and Gutzler, 1981; Gong and Ho, 2002; Zhang et al., 2009). It can be seen that both of raw ( $r 1)$ and high-frequency $(r 2)$ correlations show that the visibility and number of hazy days are correlated weakly with the winter AO, NAO and PNA. However, the visibility is highly positively correlated with EU, WP and SBH, and the number of hazy days is highly negatively correlated with EU, WP and SBH, most of which are significant at the 0.01 or 0.05 level.

Furthermore, the general characteristics of spatial distribution of the correlation coefficients between visibility and number of hazy days in BTH and the major meteorological fields from surface to tropopause in the Northern Hemisphere including SLP, U850, V850, H500, U200, T200, T150 and T70 were also examined (Figs. 3 and 4). Owning to a general anti-pattern for the number of hazy days, only the correlation maps with visibility were analyzed for simplicity. In SLP (Fig. 3a), a positive correlation center dominated most of the East Asian continent, while a negative correlation center dominated the area from northeastern Asia to the northwestern Pacific, respectively. This spatial pattern may reflect the effects of land-sea thermal contrast on the lower troposphere condition over the BTH region. The pressures increasing in the East Asian continent and decreasing in area from northeastern Asia to the northwestern Pacific suggest that they favor the visibility increase in the BTH region in winter and vice versa. In UV850 (Fig. 3b), an anomalously anti-cyclonic and northerly pattern is predominant over most of Siberia and eastern China. This suggests that an anomalous northerly advection from Siberia to eastern China improves the winter visibility in the BTH region. In H500 (Fig. 3c), there exists a " -+ - " wave train pattern along Eurasia-western Pacific at the mid-high latitude, extending from central to eastern Europe through Siberia to the northern China-Korean peninsula-Japan-northwestern Pacific Ocean, similar to the EU pattern (Wallace and Gutzler, 1981). This pattern implies that a deepening of the East Asian trough and a weakening of blocking will favor the winter visibility increase in the BTH region. In U200 (Fig. 3d), there also exists a wave train pattern from northwestern Russia through Siberia to the northwestern Pacific Ocean. This pattern may imply that the south (north) of the East Asian jet stream strengthened (weakened), coinciding with the anomalous ascending (sinking) motions that occurred in the south (north) of the jet stream entrance at the upper troposphere, which will lead to a strengthening northerly that appeared in the lower troposphere. Hence it is not conducive to the accumulation of pollutants over the $\mathrm{BTH}$ region in winter.

Besides the lower troposphere, previous studies suggested that the anomalous stratospheric warming over the Northern Hemisphere led to the severe haze pollution in eastern China in January 2013 (Wang et al., 2013). Here, the spatial distribution of the correlation coefficients between visibility and the temperature from the upper troposphere to the lower stratosphere at $200 \mathrm{hPa}$ (T200), $150 \mathrm{hPa}$ (T150), $100 \mathrm{hPa}(\mathrm{T} 100)$ and $70 \mathrm{hPa}$ (T70) were checked. Negative correlations are found from eastern Siberia to the northern North Pacific including Alaska in T200, T150, T100 and T70, respectively (Fig. 4), with the biggest correlation in T200 (Fig. 4a). The significantly negative correlation suggests that the warming at $200 \mathrm{hPa}$ over eastern Siberia to the northern North Pacific would indicate a decrease in winter visibility, namely a worsening of haze pollution in the BTH region.

Based on the above analyses, we wonder whether the meteorological variables in the significant correlation areas can be used to predict or evaluate the variability of the winter visibility and haze pollution in the BTH region. Thus, the six indices for atmospheric circulations or teleconnections were defined based on the key regions shown in the previous correlation maps as listed in Table 2. We computed the raw and high-frequency correlation coefficients of the winter visibility and number of hazy days in BTH and the six atmospheric circulation indices. All of the six indices $\left(I_{1}\right.$ to $\left.I_{6}\right)$ show highly positive or negative correlations with the winter visibility and number of hazy days, with significance at the 0.01 level (Table 3). Moreover, we note that most of the high-frequency correlations are larger than the raw correlations, except the correlations between visibility and $I_{1}$. This suggests that the links between the air quality in BTH and the circulation indices are very stable from year to year. The 

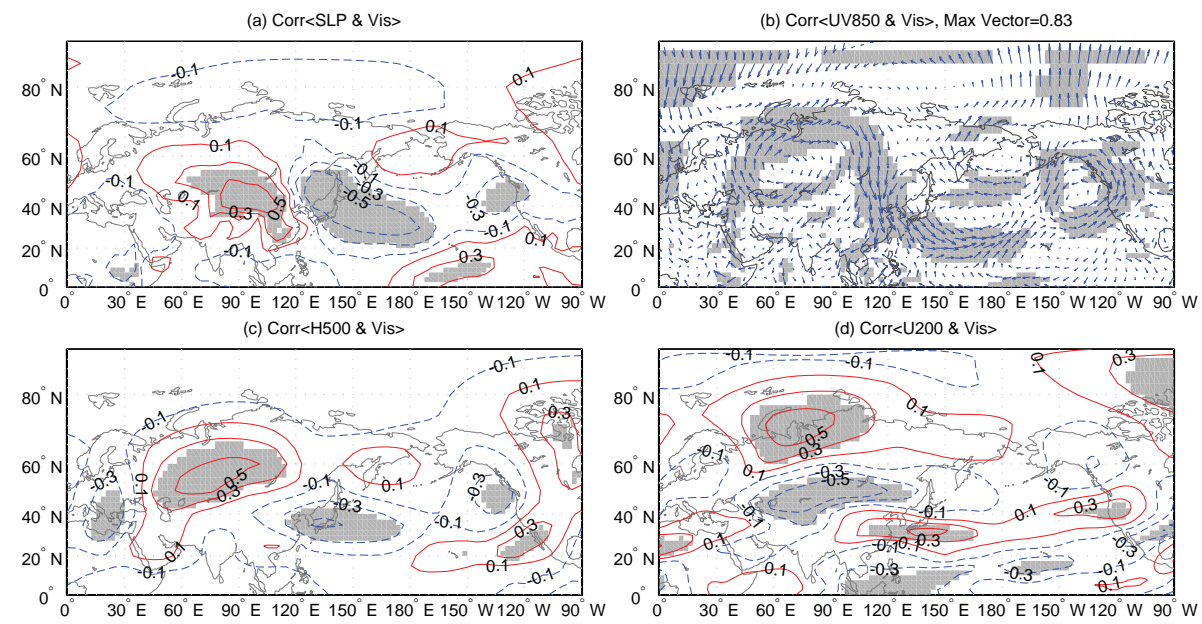

Figure 3. Spatial distribution of correlation coefficients between visibility and SLP (a), UV850 (b), H500 (c) and U200 (d) (areas significant at the 0.05 level are shaded; either U850 or V850 significant at the 0.05 level are shaded in (b)).

(a) Corr $<$ T200 \& Vis $>$
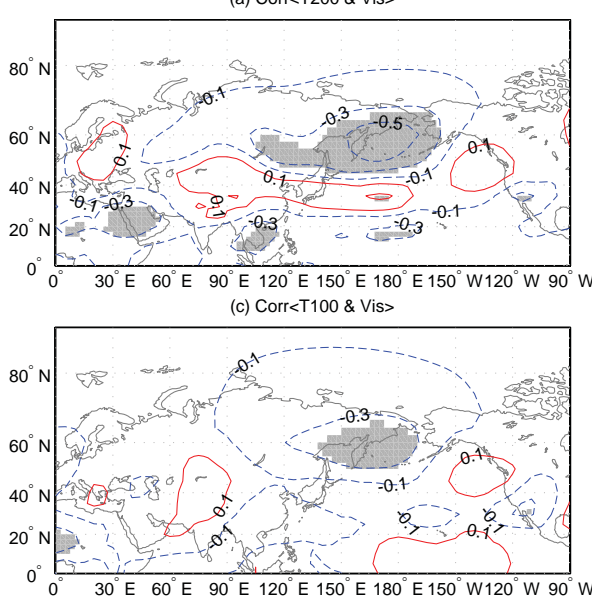
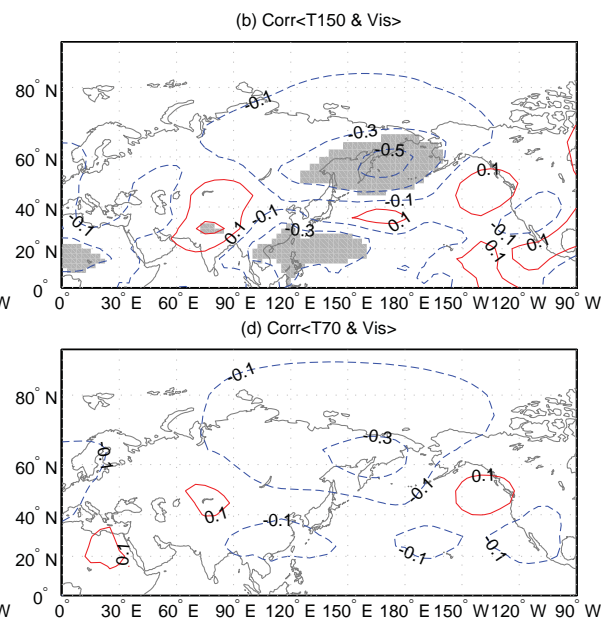

Figure 4. Spatial distribution of correlation coefficients between visibility and T200 (a), T150 (b), T100 (c) and T70 (d) (areas significant at the 0.05 level are shaded).

significantly positive or negative correlations should be a reflection of the physical response mechanisms between them, which will be discussed in the later section.

\subsection{Predictions for visibility and number of hazy days based on the circulation indices}

In order to assess the prediction capability of the six circulation indices for the winter haze pollution in BTH, the winter mean visibility and number of hazy days were estimated by applying a multivariate regression method with the least square estimate. The estimated curves by the fitting and the cross-validation with a leave-one-out method were displayed in Fig. 5. Intuitively, both of the fitting curves and the crossvalidation curves are fairly consistent with the observed winter mean visibility and number of hazy days over the last 3 decades. The raw and high-frequency correlation coeffi- cients between the observed and the fitting visibility (number of hazy days) are $0.88(0.78)$ and $0.86(0.77)$, respectively. All of them are significant at the 0.01 level. The six circulation indices together can explain $77.7 \%(78.7 \%)$ and $61.7 \%(69.1 \%)$ variances of the winter visibility and number of hazy days over the BTH region in the year-to-year (inter-annual) variability, respectively. A good fitting does not mean that there must be stable relationships between the dependent variable and explanatory variables. Thus we emphasized testing the stability of the statistic models by means of the leave-N-out cross-validations. The statistics for the cross-validation estimations were listed in Table 4, including the explained variance $\left(r^{2}\right)$, the standard error (SE), and reduction of error (RE). Previous studies suggested that RE is an extremely rigorous verification statistic because it has no lower bound, $\mathrm{RE}>0$ indicating the skillful estimation, 
Table 2. List of the definitions for the six circulation indices.

\begin{tabular}{lll}
\hline Index & Variable & Expression \\
\hline$I_{1}$ & SLP & SLP $\left(38-50^{\circ} \mathrm{N}, 84-108^{\circ} \mathrm{E}\right)-\mathrm{SLP}\left(36-52^{\circ} \mathrm{N}, 126-150^{\circ} \mathrm{E} ; 24-40^{\circ} \mathrm{N}, 150-184^{\circ} \mathrm{E}\right)$ \\
$I_{2}$ & $U_{850 \mathrm{hPa}}$ & $U_{850}\left(55-75^{\circ} \mathrm{N}, 40-110^{\circ} \mathrm{E}\right)-U_{850}\left(40-50^{\circ} \mathrm{N}, 45-75^{\circ} \mathrm{E}\right)$ \\
$I_{3}$ & $V_{850 \mathrm{hPa}}$ & $V_{850}\left(32-64^{\circ} \mathrm{N}, 104-120^{\circ} \mathrm{E}\right)$ \\
$I_{4}$ & $H_{500 \mathrm{hPa}}$ & $H_{500}\left(46-64^{\circ} \mathrm{N}, 50-92^{\circ} \mathrm{E}\right)-H_{500}\left(28-44^{\circ} \mathrm{N}, 16-28^{\circ} \mathrm{E} ; 28-42^{\circ} \mathrm{N}, 120-156^{\circ} \mathrm{E}\right)$ \\
$I_{5}$ & $U_{200 \mathrm{hPa}}$ & $U_{200}\left(42-52^{\circ} \mathrm{N}, 60-110^{\circ} \mathrm{E}\right)-U_{200}\left(64-76^{\circ} \mathrm{N}, 50-96^{\circ} \mathrm{E} ; 28-36^{\circ} \mathrm{N}, 120-152^{\circ} \mathrm{E}\right)$ \\
$I_{6}$ & $T_{200 \mathrm{hPa}}$ & $T_{200}\left(46-66^{\circ} \mathrm{N}, 146-196^{\circ} \mathrm{E}\right)$ \\
\hline
\end{tabular}

Table 3. Correlation coefficients of visibility and number of hazy days and circulation indices.

\begin{tabular}{lrrrrrrr}
\hline & & $I_{1}$ & $I_{2}$ & $I_{3}$ & $I_{4}$ & $I_{5}$ & $I_{6}$ \\
\hline Visibility & $r 1$ & $0.73^{\mathrm{a}}$ & $0.57^{\mathrm{a}}$ & $-0.76^{\mathrm{a}}$ & $0.62^{\mathrm{a}}$ & $-0.59^{\mathrm{a}}$ & $-0.61^{\mathrm{a}}$ \\
& $r 2$ & $0.70^{\mathrm{a}}$ & $0.68^{\mathrm{a}}$ & $-0.80^{\mathrm{a}}$ & $0.72^{\mathrm{a}}$ & $-0.62^{\mathrm{a}}$ & $-0.62^{\mathrm{a}}$ \\
\hline Number of hazy days & $r 1$ & $-0.60^{\mathrm{a}}$ & $-0.47^{\mathrm{a}}$ & $0.60^{\mathrm{a}}$ & $-0.47^{\mathrm{a}}$ & $0.52^{\mathrm{a}}$ & $0.60^{\mathrm{a}}$ \\
& $r 2$ & $-0.61^{\mathrm{a}}$ & $-0.65^{\mathrm{a}}$ & $0.69^{\mathrm{a}}$ & $-0.67^{\mathrm{a}}$ & $0.58^{\mathrm{a}}$ & $0.64^{\mathrm{a}}$ \\
\hline
\end{tabular}

a Same as Table 1.

$\mathrm{RE}>0.2$ indicating the reliable estimation and $\mathrm{RE}=1.0$ indicating a perfect estimation (Fritts, 1976; Gong and Luterbacher, 2008; Zhang et al., 2010).

The statistics for both the visibility and number of hazy days are generally stable (no sharp increase or decrease) when $N$ increased from 1 to 11 (more than $30 \%$ of the sample removed in regression models), although the $r^{2}$ and RE (SE) slightly decreased (increased) with the increase in $N$. For the visibility, the $r^{2}$ varied from 52.5 to $62.7 \%$ with an average of $57.6 \%$, the SE varied from 0.74 to 0.84 with an average of 0.79 , the RE varied from 0.49 to 0.61 with an average of 0.55 . For the number of hazy days, the $r^{2}$ varied from 31.1 to $41.5 \%$ with an average of $35.2 \%$, the SE varied from 3.37 to 3.66 with an average of 3.54 , and the RE varied from 0.23 to 0.38 with an average of 0.30 . The mild changes in these statistics suggest that the statistic models between the given atmospheric circulations and the haze pollution indicators are stable even in the case of parts of sample missed. On the other hand, we noted that the statistics for the visibility estimations are generally better than those for the number of hazy day estimations in all tests. However, the minimum values of $r^{2}$ and RE for the number of hazy day estimations are still larger than $30 \%$ and 0.2 , respectively. Based on these statistics, it can be concluded that the predictions for the winter visibility and number of hazy days in the BTH region based on the circulation indices are overall reliable during the entire period, especially for the mean visibility. That is to say, the winter haze pollution in BTH can be evaluated or estimated well by the optimized atmospheric circulations.

The relatively larger errors for the estimated values that referred to the observed visibility and number of hazy days have been found since the winter in 2009 (Fig. 5). We re- computed all the statistics for the period 1981 to 2008; the results showed that all the values of $r^{2}$ and RE (SE) for visibility and the number of hazy day predictions increased (decreased) much more than the entire period (Table 4), suggesting that the statistic estimation models are much more stable and reliable before 2009. Why did the prediction efficiency of the statistic estimation models decrease relatively in the last few years? We can discern that the estimations for the winter mean visibility are distinctly lower (higher) than those observed in the winters of 2009 and 2010 (2014), and vice versa for the number of hazy days. We speculated that these phenomena can be attributed partly to the fluctuations of pollutant emissions because the pollutant emissions over northern China around 2008 were controlled strictly by the Chinese government, associated with the 2008 Olympic Games in Beijing (An et al., 2007; Zhang et al., 2010; Gao et al., 2011). The decrease in pollutant emissions led to the improvement of air quality (increasing visibility and decreasing number of hazy days) in 2009 and 2010, although the atmospheric conditions remained the same and did not contribute to the spread and elimination of air pollutants. However, pollutant emissions, especially in the areas of BTH, rebounded after the Olympic Games, with the decrease in visibility and increase in hazy days in the BTH region around 2012 to 2014 to some extent (Z. Y. Zhang et al., 2015). Generally, the errors between the observed visibility (haze days) and the predicted one could be attributed to the natural variability of atmospheric circulation and the changes in pollutant emissions. However, the contribution rates of each factor are not clear now; thus, further studies will be necessary to unravel these issues. 
Table 4. List of the statistics for the leave-N-out cross-validation estimations.

\begin{tabular}{cccccccccc}
\hline \multirow{2}{*}{$N$} & Period covered & \multicolumn{3}{c}{ Visibility } & & \multicolumn{3}{c}{ Number of hazy days } \\
\cline { 3 - 4 } \cline { 8 - 10 } & & $r^{2}(\%)$ & SE & RE & & $r^{2}(\%)$ & SE & RE \\
\hline \multirow{2}{*}{1} & $1981-2015$ & 62.7 & 0.74 & 0.61 & & 41.5 & 3.37 & 0.38 \\
& $1981-2008$ & 87.1 & 0.42 & 0.87 & & 53.9 & 2.56 & 0.52 \\
\hline 3 & $1981-2015$ & 56.8 & 0.80 & 0.54 & & 34.3 & 3.57 & 0.28 \\
& $1981-2008$ & 86.8 & 0.42 & 0.87 & & 52.6 & 2.59 & 0.51 \\
\hline 5 & $1981-2015$ & 59.2 & 0.78 & 0.57 & & 35.3 & 3.54 & 0.30 \\
& $1981-2008$ & 86.8 & 0.42 & 0.87 & & 46.7 & 2.75 & 0.43 \\
\hline 7 & $1981-2015$ & 59.0 & 0.78 & 0.56 & & 37.5 & 3.48 & 0.33 \\
& $1981-2008$ & 86.4 & 0.43 & 0.86 & & 44.7 & 2.80 & 0.41 \\
\hline 9 & $1981-2015$ & 56.2 & 0.80 & 0.54 & & 32.5 & 3.62 & 0.27 \\
& $1981-2008$ & 84.2 & 0.46 & 0.84 & & 40.8 & 2.90 & 0.36 \\
\hline \multirow{2}{*}{11} & $1981-2015$ & 52.5 & 0.84 & 0.49 & & 31.1 & 3.66 & 0.23 \\
& $1981-2008$ & 84.4 & 0.46 & 0.84 & & 48.2 & 2.71 & 0.44 \\
\hline
\end{tabular}

$N$ denotes the number of samples removed in the cross-validation regressions; only the odd numbers of $N$ were listed for short.

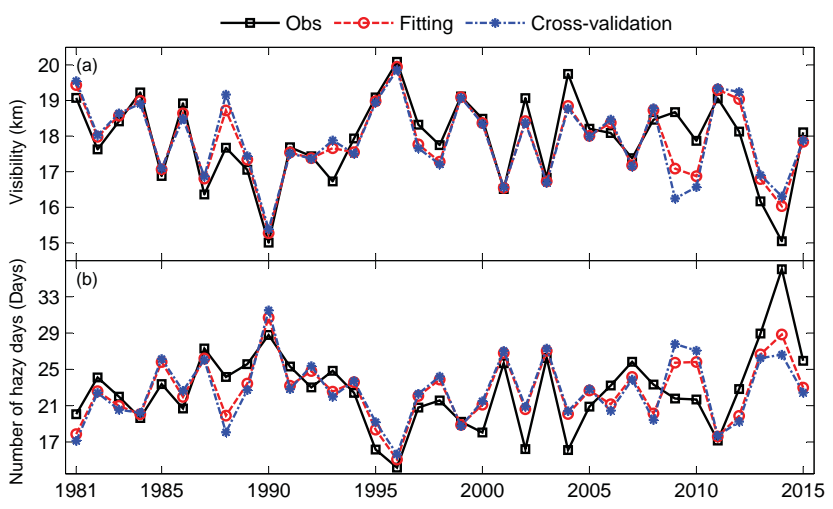

Figure 5. Curves of the observed and predicted winter visibility (a) and number of hazy days (b) in the BTH region since 1981.

\subsection{Possible mechanism of the circulations related to the winter haze pollution}

In order to explore the possible mechanism and role of the investigated circulation indices in the winter visibility and number of hazy days in the BTH region, the links between the given large-scale atmospheric circulations and the local meteorological conditions, which have close relations to the haze pollution, were examined. For simplicity, a comprehensive index labeled $I_{\mathrm{c}}$ was synthesized from the six individual circulation indices ( $I_{1}$ to $\left.I_{6}\right)$ by applying a PCA method, namely the first principal component (PC1). The high values of the explained variance ( $64.4 \%$ in PC1) indicated that the comprehensive index of $I_{\mathrm{c}}$ roughly reflects the integrated features of all six indices. Thus, we used the $I_{\mathrm{c}}$ instead of the six individual indices in the following analysis. Generally, the positive (negative) $I_{\mathrm{c}}$ indicate the lower (higher) visibility and more (fewer) hazy days in the BTH region in winter.

First we examined the links between the $I_{\mathrm{c}}$ and the meteorological fields of SLP and H500, respectively. Based on the NCEP/NCAR reanalysis data, Fig. 6a and b present the climatological mean of SLP and H500 in winter averaged from 1981 to 2010, respectively. The changes in SLP and H500 in winter in association with a 1 standard deviation positive $I_{\mathrm{c}}$ during the winters of 1981 to 2015 are shown in Fig. $6 \mathrm{c}$ and d, respectively. In the climatological mean fields, the BTH region was located in the axis of the East Asian trough at the middle troposphere and in the ridge of the Siberian-Mongolia high in the SLP field, which indicates that the northerly dominated the BTH region in winter. The regression maps show that the SLP decreased in the Siberian-Mongolia high areas and increased in the western Pacific in the SLP, and the geopotential height decreased in most areas of Siberia and increased in northern China to the western Pacific. These patterns suggest that both the East Asian trough and the Siberian high weaken with increasing $I_{\mathrm{c}}$, which further implies that the winter cold air activity will be weakened and then lead to anomalous steady atmospheric conditions in BTH and its adjacent areas in winter. That is, the less strong Siberian high and East Asian trough and the associated northerly winds in the low and middle troposphere will lead to severe haze pollution (lower visibility and more hazy days) due to the favorable meteorological conditions for the accumulation and chemical reaction of pollutants. Anyway, we wonder whether it is true, as we speculated. We further examined the links between the comprehensive index of $I_{\mathrm{c}}$ and the local meteorological conditions that play direct roles in the formation of haze pollution, including the wind 
fields (Fig. 7), relative humidity (Fig. 8) and vertical velocity (Fig. 9) at the lowest troposphere (averaged from 1000 to $900 \mathrm{hPa}$ with an interval of $25 \mathrm{hPa}$ ) and the boundary layer height (Fig. 10) based on the ERA-Interim reanalysis data.

Figure 7a displays the climatological mean wind field averaged from 1000 to $900 \mathrm{hPa}$ over winter 1981 to 2010 . At the lower level, the northwesterly winds dominated BTH, and the wind speed in Beijing, Tianjin and the north of Hebei province was larger than that in the south of Hebei province. Figure $7 \mathrm{~b}$ shows the composite (positive $I_{\mathrm{c}}$ winters minus negative $I_{\mathrm{c}}$ winters) wind field averaged from 1000 to $900 \mathrm{hPa}$ over winter 1981 to 2015 . In the composite wind field, the anomalous southeasterly winds dominated the BTH region instead of the northwesterly in the climatological mean wind field, indicating that the northwesterly weakened significantly over BTH and its neighboring areas when $I_{\mathrm{c}}$ increased. Previous studies (Z. Y. Zhang et al., 2015) demonstrated that the decrease in wind speed is not conducive to the diffusion of air pollutants and easily leads to haze pollution in Beijing. It may be true for the whole BTH region. Thus, the increase in $I_{\mathrm{c}}$ will lead to a decrease in the visibility and an increase in the number of hazy days in winter over the BTH region.

As with Fig. 7, Fig. 8a and b present the climatology and composite relative humidity averaged from the lowest troposphere, respectively. In the composite map, all the areas of BTH are covered by the positive values, and most of them are significant at the 0.05 level. They indicate that the winter relative humidity was anomalously higher in the positive $I_{\mathrm{c}}$ years than that in the negative $I_{\mathrm{c}}$ years. As pointed out in the Introduction, a high relative humidity is one of the important reasons for visibility degradation. This is because the high relative humidity is favorable for the accumulation and hygroscopic growth of pollutants, which can strengthen the light scattering and absorption by atmospheric particles and gases and then cause the visibility degradation directly (Baumer et al., 2008; Q. Zhang et al., 2015). Thus a positive $I_{\mathrm{c}}$ implies that a decrease in visibility accompanied by the increasing number of hazy days may occur in winter over the BTH region. Figure 9a and b present the climatology and composite vertical speeds averaged from the lowest troposphere, respectively. The positive (negative) values of vertical speed in the unit of $\mathrm{Pa} \mathrm{s}^{-1}$ denote sinking (ascending) motion. The climatological vertical speeds show that the downward air motions dominated the BTH region in winter. In the composite vertical speed field, most areas of BTH were covered by the significantly negative values, which suggested that fewer vertical exchanges of air occurred in these areas in the positive $I_{\mathrm{c}}$ winters. In other words, the increased $I_{\mathrm{c}}$ may result in a weaker vertical convection and force the lowest troposphere to be more stable. It is easy to understand that the anomalous stabilization will lead to much haze pollution. Moreover, a similar result can be found in the planetary boundary layer height, which was reduced significantly in most of BTH and its adjacent areas in the positive $I_{\mathrm{c}}$ winters
(Fig. 10). The decreased boundary layer height will depress the air pollutants into a narrower air column in a certain area and then lead to an increase in the pollutants' concentration. Thus, a winter with lower visibility and more hazy days in the BTH region would be expected in the case of the lower boundary layer height caused by the anomalously high $I_{\mathrm{c}}$.

In view of the responses of the local surface winds, relative humidity, vertical motion and boundary layer to the comprehensive index of $I_{\mathrm{c}}$ mentioned above, the close relationships between the winter mean visibility and number of hazy days over the BTH region and the given six atmospheric circulations are generally feasible in the physical mechanism. It is reasonable and reliable to estimate the winter haze pollution in the BTH region based on the seasonal forecast fields derived from climate simulation. Thus it will be helpful to provide scientific references for the governmental decisions in advance about the reducing or controlling of pollutant emission to deal with the probably severe haze pollution in the BTH region.

\section{Conclusions}

Using the daily visibility and number of hazy days recorded in the 19 meteorological stations and the NCEP/NCAR and ERA-Interim reanalysis data, the evolution of the winter haze pollution in the BTH region since 1981 and its possible relations to atmospheric circulations were examined in this study.

The results showed that the winter mean visibility has a significant negative correlation with the number of hazy days, and both of them show distinctly inter-annual variability during the entire period 1981 to 2015 . The correlation coefficients between the winter haze pollution (the visibility and number of hazy days) and the most common atmospheric circulations over the mid-high latitude of the Northern Hemisphere were re-examined. Results showed that the relations between the haze pollution in $\mathrm{BTH}$ and the winter $\mathrm{AO}, \mathrm{NAO}$ and PNA were very weak, but that they were correlated significantly with EU, WP and SBH. Furthermore, the six new indices $\left(I_{1}\right.$ to $\left.I_{6}\right)$ derived from the key areas in the fields of SLP, U\&V850, H500, U200 and T200 were closely related to the winter haze pollution in BTH. We can estimate the visibility and number of hazy days by using the six indices and the fitting and leave-N-out cross-validation methods, respectively. In general, the high level of the estimation statistics suggested that the winter haze pollution in BTH can be estimated or predicted to a reasonable degree based on the optimized atmospheric circulation indices. However, we also noted that the statistic estimation models for the visibility and number of hazy days may be influenced in part by a prominent change in the pollutants' emission artificially. Thus, it is valuable and significant for government decisionmaking departments to take action in advance in dealing with the probably severe haze pollution in BTH indicated by the 

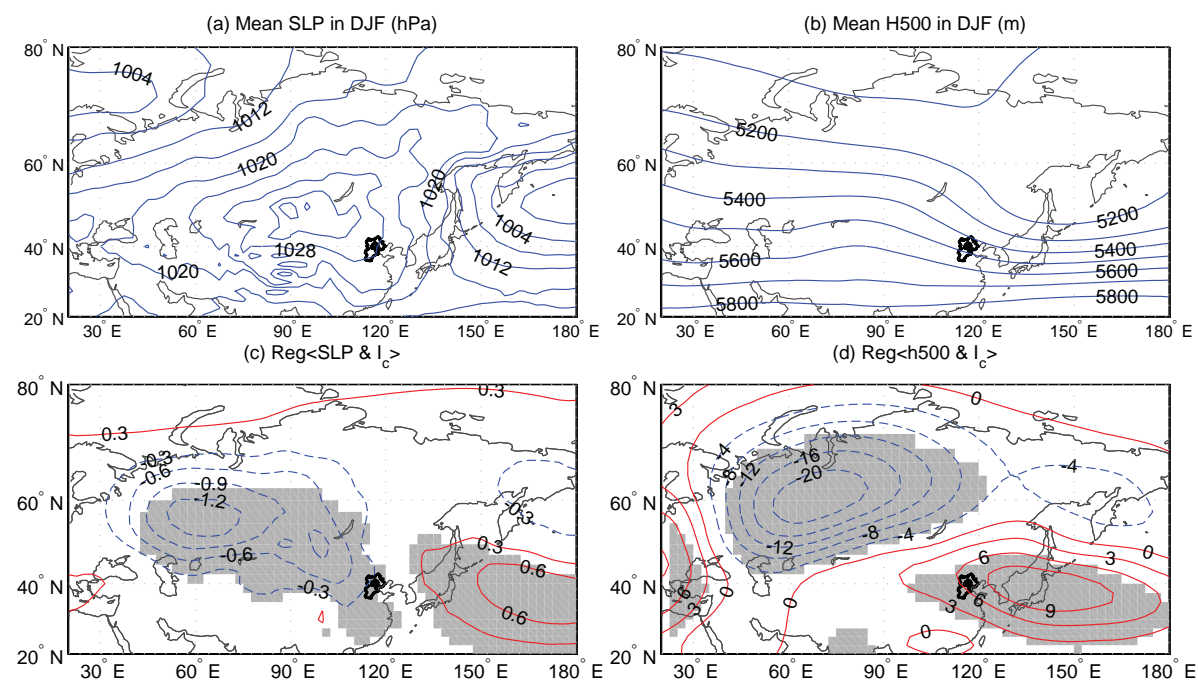

Figure 6. The climatological mean fields of SLP (a) and H500 (b) averaged in winter 1981 to 2010, and the spatial distribution of the regression coefficients of SLP (c) and H500 (d) upon the $I_{\mathrm{c}}$ over the period 1981 to 2015 (areas significant at the 0.05 level are shaded).
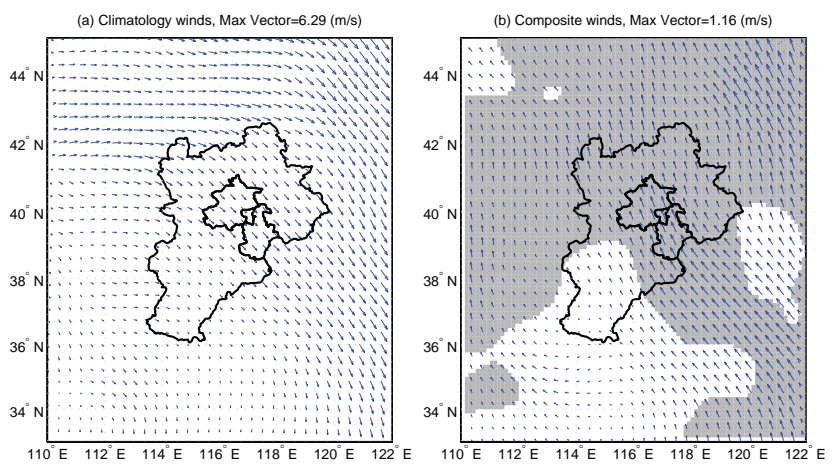

Figure 7. The climatological mean (a) and the composite (b) wind fields averaged from 1000 to $900 \mathrm{hPa}$ (areas significant at the 0.05 level are shaded).
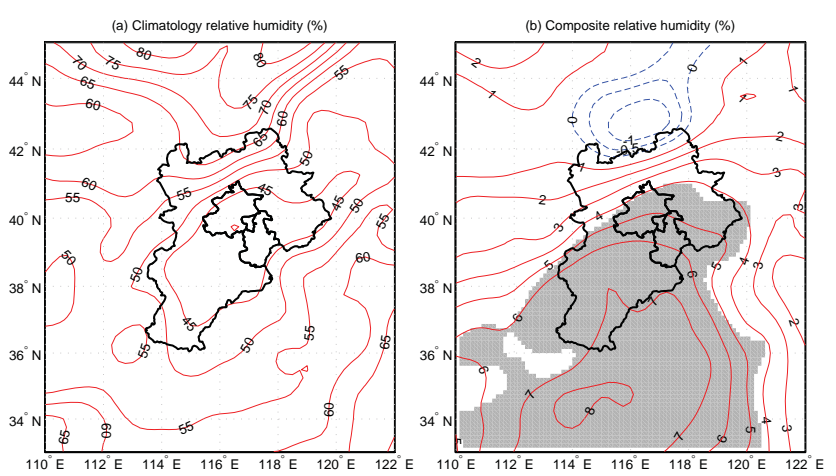

Figure 8. Same as Fig. 7 but for relative humidity.

circulation conditions, such as in controlling the pollutants' discharge.
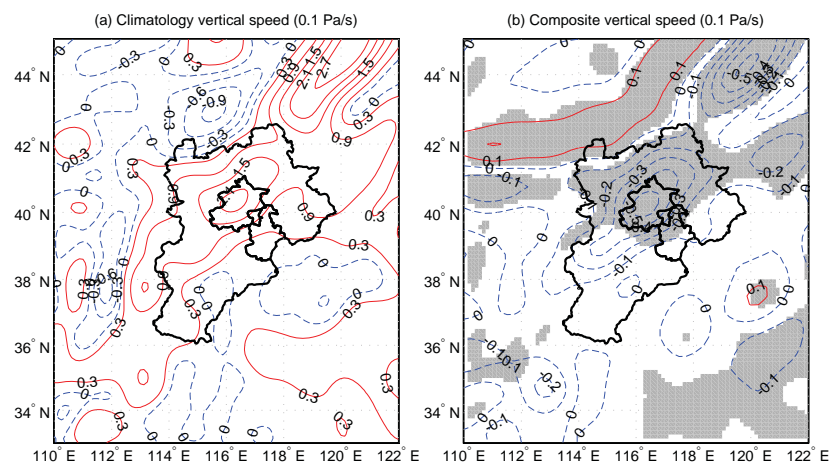

Figure 9. Same as Fig. 7 but for vertical speed.

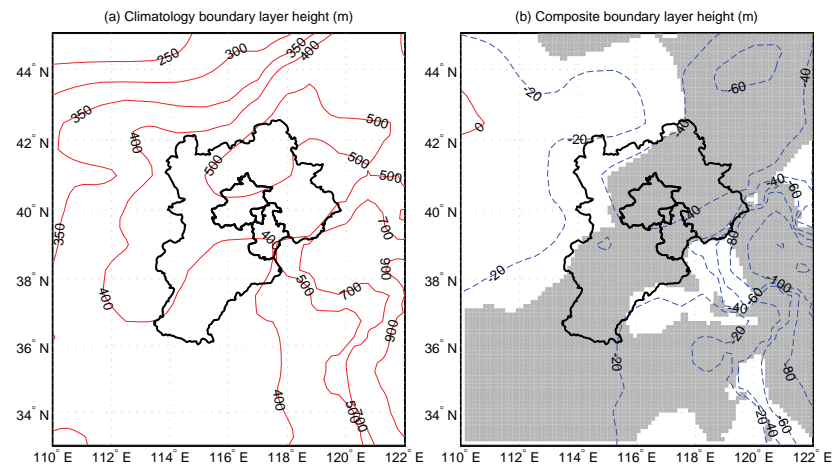

Figure 10. The climatological mean (a) and the composite (b) boundary layer height (areas significant at the 0.05 level are shaded).

In order to investigate the link processes between the haze pollution and the given atmospheric circulations more simply, a comprehensive index $\left(I_{\mathrm{c}}\right)$ was synthesized from the 
six individual circulation indices by applying a PCA method. The winter $I_{\mathrm{c}}$ increase appears to cause a shallowing of the East Asian trough at the middle troposphere and a weakening of the Siberian high-pressure field at sea level, and is then accompanied by a reduction (increase) of horizontal advection and vertical convection (relative humidity) in the lowest troposphere and a reduced boundary layer height in BTH and its neighboring areas, which are not conducive to the spread and elimination of air pollutants, but favor the formation of haze pollution in BTH winter. In short, the reasonable link processes and the stable statistic relationships suggested that the atmospheric circulation indices can be used to predict or evaluate generally the haze pollution in BTH winter to some extent.

Acknowledgements. This study was supported by the Beijing Natural Science Foundation (grant no. 8152019), the National Key Technologies R \& D Program of China (grant nos. 2014BAC23B01 and 2014BAC23B00) and project PE16010 of the Korea Polar Research Institute. X. Zhang acknowledges the financial support from project Z141100001014013 of the Beijing Municipal Science \& Technology Commission. D. Gong was supported by the National Natural Science Foundation of China (grant no. 41321001).

Edited by: G. Carmichael

\section{References}

An, X., Zhu, T., Wang, Z., Li, C., and Wang, Y.: A modeling analysis of a heavy air pollution episode occurred in Beijing, Atmos. Chem. Phys., 7, 3103-3114, doi:10.5194/acp-7-3103-2007, 2007.

Baddock, M. C., Strong, C. L., Leys, J. F., Heidenreich, S. K., Tews, E. K., and McTainsh, G. H.: A visibility and total suspended dust relationship, Atmos. Environ., 89, 329-336, 2014.

Baumer, D., Vogel, B., Versick, S., Rinke, R., Mohler, O., and Schnaiter, M.: Relationship of visibility, aerosol optical thickness and aerosol size distribution in an ageing air mass over SouthWest Germany, Atmos. Environ., 42, 989-998, 2008.

Chan, C. K. and Yao, X.: Air pollution in mega cities in China, Atmos. Environ., 42, 1-42, 2008.

Chang, D., Song, Y., and Liu, B.: Visibility trends in six megacities in China 1973-2007, Atmos. Res., 94, 161-167, 2009.

Chen, Y., Zhao, C. S., Zhang, Q., Deng, Z. Z., Huang, M. Y., and Ma, X. C.: Aircraft study of mountain chimney effect of Beijing, China, J. Geophys. Res., 114, D08306, doi:10.1029/2008JD010610, 2009.

Dee, D. P., Uppala, S. M., Simmons, A. J., Berrisford, P., Poli, P., Kobayashi, S., Andrae, U., Balmaseda, M. A., Balsamo, G., Bauer, P., Bechtold, P., Beljaars, A. C. M., Berg, L., Bidlot, J., Bormann, N., Delsol, C., Dragani, R., Fuentes, M., Geer, A. J., Haimberger, L., Healy, S. B., Hersbach, H., Hólm, E. V., Isaksen, L., Kållberg, P., Köhler, M., Matricardi, M., McNally, A. P., Monge-Sanz, B. M., Morcrette, J. J., Park, B. K., Peubey, C., Rosnay, P., Tavolato, C., Thépaut, J. N., and Vitart, F.: The ERAInterim reanalysis: Configuration and performance of the data assimilation system, Q. J. Roy. Meteorol. Soc., 137, 553-597, 2011.

Deng, J. J., Xing, Z. Y., Zhuang, B. L., and Du, K.: Comparative study on long-term visibility trend and its affecting factors on both sides of the Taiwan Strait, Atmos. Res., 143, 266-278, 2014.

Feng, J. L., Hu, M., Chan, C. K., Lau, P. S., Fang, M., He, L. Y., and Tang, X. Y.: A comparative study of the organic matter in PM2.5 from three Chinese megacities in three different climatic zones, Atmos. Environ., 40, 3983-3994, 2006.

Fritts, H. C.: Tree-Rings and Climate, Academic Press, London, 567 p., 1976.

Gao, Y., Liu, X., Zhao, C., and Zhang, M.: Emission controls versus meteorological conditions in determining aerosol concentrations in Beijing during the 2008 Olympic Games, Atmos. Chem. Phys., 11, 12437-12451, doi:10.5194/acp-11-12437-2011, 2011.

Gong, D. Y. and Ho, C. H.: Siberian High and climate change over middle to high latitude Asia, Theor. Appl. Climatol., 72, 1-9, 2002.

Gong, D. Y. and Luterbacher, J.: Variability of the low-level crossequatorial jet of the western Indian Ocean since 1660 as derived from coral proxies, Geophys. Res. Lett., 35, L01705, doi:10.1029/2007GL032409, 2008.

Kalnay, E., Kanamitsu, M., Kistler, R., Collins, W., Deaven, D., Gandin, L., Iredell, M., Saha, S., White, G., Woollen, J., Zhu, Y., Leetmaa, A., Reynolds, B., Chelliah, M., Ebisuzaki, W., Higgins, W., Janowiak, J., Mo, K. C., Ropelewski, C., Wang, J., Jenne, R., and Joseph, D.: The NCEP/NCAR 40-year reanalysis project, B. Am. Meteorol. Soc., 77, 437-471, 1996.

Kang, H. Q., Zhu, B., Su, J. F., Wang, H. L., Zhang, Q. C., and Wang, F.: Analysis of a long-lasting haze episode in Nanjing, China, Atmos. Res., 120, 78-87, 2013.

Liu, S. H., Liu, Z. X., Li, J., Wang, Y. C., Ma, Y. J., Sheng, L., Liu, H.P., Liang, F. M., Xin, G. J., and Wang, J. H.: Numerical simulation for the coupling effect of local atmospheric circulations over the area of Beijing, Tianjin and Hebei Province, Sci. China Ser. D-Earth, 52, 382-392, 2009.

Lo, J. C. F., Lau, A. K. H., Fung, J. C. H., and Chen, F.: Investigation of enhanced cross-city transport and trapping of air pollutants by coastal and urban land-sea breeze circulations, J. Geophys. Res., 111, D14104, doi:10.1029/2005JD006837, 2006.

Miao, Y. C., Liu, S. H., Zheng, Y. J., Wang, S., Chen, B. C., Zheng, H., and Zhao, J. C.: Numerical study of the effects of local atmospheric circulations on a pollution event over Beijing-TianjinHebei, China, J. Environ. Sci., 30, 9-20, 2015.

Sabetghadam, S., Farhang, A. G., and Golestani, Y.: Visibility trends in Tehran during 1958-2008, Atmos. Environ., 62, 512520, 2012.

Schichtel, B. A., Husar, R. B., Falke, S. R., and Wilson, W. E.: Haze trends over the United States 1980-1995, Atmos. Environ., 35, 5205-5210, 2001.

Streets, D. G., Fu, J. H. S., Jang, C. J., Hao, J., He, K. B., Tang, X. Y., Zhang, Y. H., Wang, Z. F., Li, Z. P., Zhang, Q., Wang, L. T., Wang, B. Y., and Yu, C.: Air quality during the 2008 Beijing Olympic Games, Atmos. Environ., 41, 480-492, 2007.

Wallace, J. M. and Gutzler, D. S.: Teleconnections in the geopotential height field during the Northern Hemisphere winter, Mon. Weather Rev., 109, 784-812, 1981. 
Wang, H. J., Chen, H. P., and Liu, J. P.: Arctic Sea Ice Decline Intensified Haze Pollution in Eastern China, Atmos. Oceanic Sci. Lett., 8, 1-9, 2015.

Wang, T., Nie, W., Gao, J., Xue, L. K., Gao, X. M., Wang, X. F., Qiu, J., Poon, C. N., Meinardi, S., Blake, D., Wang, S. L., Ding, A. J., Chai, F. H., Zhang, Q. Z., and Wang, W. X.: Air quality during the 2008 Beijing Olympics: secondary pollutants and regional impact, Atmos. Chem. Phys., 10, 7603-7615, doi:10.5194/acp10-7603-2010, 2010.

Wang, Y., Hao, J., McElroy, M. B., Munger, J. W., Ma, H., Chen, D., and Nielsen, C. P.: Ozone air quality during the 2008 Beijing Olympics: effectiveness of emission restrictions, Atmos. Chem. Phys., 9, 5237-5251, doi:10.5194/acp-9-5237-2009, 2009.

Wang, Y. S., Yao, L., Liu, Z. R., Ji, D. S., Wang, L. L., and Zhang, J. K.: Formation of haze pollution in Beijing-Tianjin-Hebei region and their control strategies, Chin. Sci. Bull., 28, 353-363, 2013 (in Chinese).

Wen, C. C. and Yeh, H. H.: Comparative influences of airborne pollutants and meteorological parameters on atmospheric visibility and turbidity, Atmos. Res., 96, 496-509, 2010.

Wu, D.: Hazy weather research in China in the last decade: a review, Acta Sci. Circumst., 32, 257-269, 2012 (in Chinese).

Wu, D., Chen, H. Z., Wu, M., Liao, B. T., Wang, Y. C., Liao, X. N., Zhang, X. L., Quan, J. N., Liu, W. D., Gu, Y., Zhao, X. J., Meng, J. P., and Sun, D.: Comparison of three statistical methods on calculating hazy days-taking areas around the capital for example, China Environ. Sci., 34, 545-554, 2014 (in Chinese).

Xu, W. Z., Chen, H., Li, D. H., Zhao, F. S., and Yang, Y.: A case study of aerosol characteristics during a haze episode over Beijing, Procedia, Environ. Sci., 18, 404-411, 2013.
Zhang, Q. H., Zhang, J. P., and Xue, H. W.: The challenge of improving visibility in Beijing, Atmos. Chem. Phys., 10, 78217827, doi:10.5194/acp-10-7821-2010, 2010.

Zhang, Q., Quan, J. L., Tie, X. X., Li, X., Liu, Q., Gao, Y., and Zhao, D. L.: Effects of meteorology and secondary particle formation on visibility during heavy haze events in Beijing, China, Sci. Total Environ., 502, 578-584, 2015.

Zhang, X. L., Huang, Y. B., Zhu, W. Y., and Rao, R. Z.: Aerosol characteristics during summer haze episodes from different source regions over the coast city of North China Plain, J. Quant. Spectrosc. R., 122, 180-193, 2013.

Zhang, Z. Y., Gong, D. Y., Hu, M., Guo, D., He., X. Z., and Lei, Y. N.: Anomalous winter temperature and precipitation events in southern China, J. Geogra. Sci., 19, 471-488, 2009.

Zhang, Z. Y., Gong, D. Y., He, X. Z., Lei, Y. N., and Feng, S. H.: Statistical reconstruction of Antarctic Oscillation index based on multi-proxies, Atmos. Oceanic Sci. Lett., 3, 283-287, 2010.

Zhang, Z. Y., Zhang, X. L., Gong, D. Y., Quan, W. J., Zhao, X. J., Ma, Z. Q., and Kim, S. J.: Evolution of surface $\mathrm{O}_{3}$ and $\mathrm{PM}_{2.5}$ concentrations and their relationships with meteorological conditions over the last decade in Beijing, Atmos. Environ., 108, 67-75, 2015.

Zhao, X. J., Zhang, X. L., Xu, X. F., Xu, J., Meng, W., and Pu, W. $\mathrm{W}$.: Seasonal and diurnal variations of ambient $\mathrm{PM}_{2.5}$ concentration in urban and rural environments in Beijing, Atmos. Environ., 43, 2893-2900, 2009.

Zhao, X. J., Zhao, P. S., Xu, J., Meng, W., Pu, W. W., Dong, F., He, D., and Shi, Q. F.: Analysis of a winter regional haze event and its formation mechanism in the North China Plain, Atmos. Chem. Phys., 13, 5685-5696, doi:10.5194/acp-13-5685-2013, 2013. 